\title{
Workshop: The Cultural Politics of Climate Change: What is Next for the Planet's Future?
}

\section{Professor Imre Szeman currently holds the Canada Research Chair in Cultural Studies at the University of Alberta. He is co-editor of Energy Humanities: A Reader (Johns Hopkins University Press), Fueling Culture: Energy, History, Politics (Fordham University Press) and Petrocultures: Oil, Energy, Culture (McGill-Queen's University Press) [all forthcoming in 2016], and is completing On Empty: The Cultural Politics of Oil (Fordham), in addition to other works.}

\section{Thursday Nov. 26, 2015 I 7:00-9:00pm Room: HC 1530 \\ Harbour Centre, Simon Fraser University 515 W. Hastings St.}

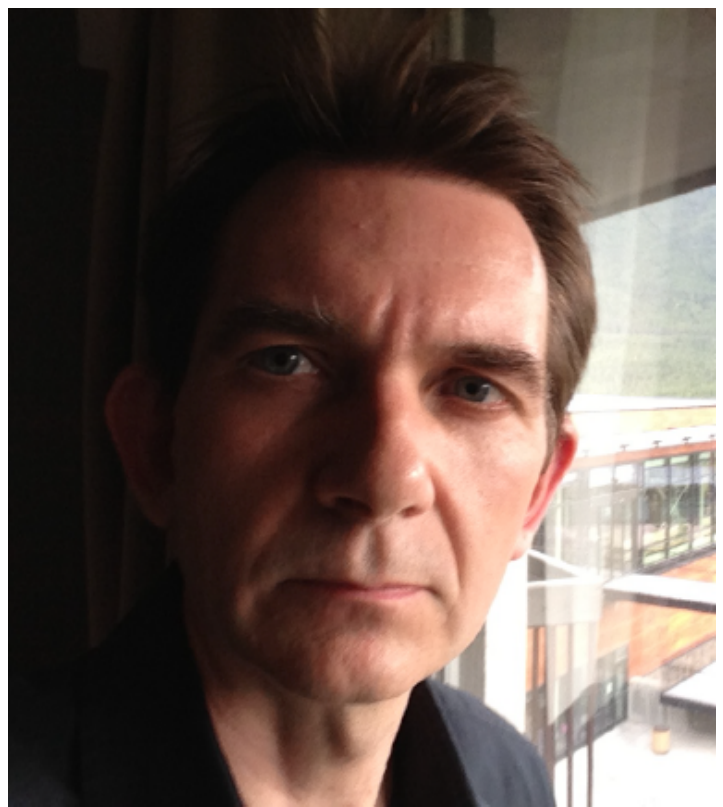

The upcoming UN Conference on Climate Change in Paris (COP21) is expected to be a turning point in humanity's response to environmental crisis. Or at least that's the hope. COP21 aims to achieve a legally binding, international agreement on climate applicable to all countries. Yet even if COP achieves its desired outcome-a very big if - some of the most significant issues related to global warming are unlikely to be addressed. The UN climate process remains committed to dealing with environmental crisis within the bounds of existing socio-economic structures; most countries, for instance, intend to use market mechanisms to enact the terms of the climate agreement.

Can we move really move forward on climate change while retaining the systems and practices that have brought us to the brink of disaster? Or do we need to push for more substantial changes-ones that will have an impact on the environment as well as social justice and equality?

Please join Dr. Imre Szeman and the Center for Policy Studies on Culture and Communities for an open discussion about challenges facing action on climate change today. Dr. Szeman is co-director of the Petrocultures Research Cluster at the University of Alberta, a group that explores the changes to values, behaviors, and expectations that will need to take place in order to effect energy transition. In addition to discussing the cultural components of energy transition left out of COP21, Dr. Szeman is eager to discuss the challenges of mobilizing knowledge about climate change-not just scientific information about planetary systems, but insights into (for example) belief, affect, politics, and social divisions on the capacity for socio-political transformation today.

*To access a selection of Dr. Szeman's publications and other relevant readings for this workshop, please visit the CPCC website: http://www.sfu.ca/fcat/research-centres-institutes/cpcc/events.html. 